\title{
Social Information in the Context of the Negative Impact
}

\author{
Mironova O.V. \\ University of management "TISBI" \\ Kazan, Russia \\ Busolga78@mail.ru
}

\author{
Galeeva M.Z. \\ University of management "TISBI" \\ Kazan, Russia \\ mzodo@rambler.ru
}

\author{
Kalinkina T.E. \\ University of management "TISBI" \\ Kazan, Russia \\ tatjana_kalinkina@mail.ru
}

\begin{abstract}
The negative aspect of the information concept reflects the relationship of information and its consumer, information compliance management goals, which is implemented on its basis. The negative properties of information are manifested only in the presence of the information unity, the user and the purpose of management.

The value and usefulness of using information is in the development (consumer) solutions to achieve their goals. From this point of view, the consumer properties of information are analyzed. This form of adequacy is directly related to the practical use of information, with the correspondence of its target function of the system.
\end{abstract}

Keywords-communication practice; understanding; negative impact; social information; society.

\section{INTRODUCTION}

The problem of the negative impact of social information and mass communication worries many scientists.

The problems of culture and mass communication occupied a prominent place in the works of the Frankfurt school theorists. The main ideas of this direction, as you know, began to form in the period between the two world wars. The main representatives are Max Horkheimer, Theodor Adorno and Herbert Marcuse.

According to Adorno and Horkheimer, in the conditions of modern capitalism comprehensive penetration and use of instrumental rationality, science, technological achievements often stimulate negative trends. The world becomes, in fact, the subject of technical regulation, and the man himself is a continuation of this world. Forms of social domination are increasingly sophisticated and effective [1, 67].

In these conditions, from the point of Frankfurt view, people are increasingly dependent on the processes of increasing rationality. Everyday human life in all its manifestations is characterized by isolation of people and domination of various technological forms.
The cultural industry plays a significant role in this regard. In the concept of "culture industry" recorded a new quality of cultural forms. They appeared with the development of entertainment and consumption in the early to mid-twentieth century. This was determined by the conditions of modern capitalism, when the laws of the market are decisive for all spheres of society, including the sphere of culture.

The following circumstance is essential. Whereas previously the art field retained a certain autonomy in relation to the market, which allowed it to perform some critical function in society, in the conditions of subordination of culture to the logic of commodity exchange, this autonomy disappears. Works of art in their new, marketable form become part of people's daily lives. It is inevitably associated with the erosion of the authentic artistic value of these works. This leads to the argument that cultural values as such, on the one hand, and the activities of the mass media, on the other, are "non-contiguous" phenomena.

Mass production of cultural forms involves the unification of individual characteristics. It in turn, is associated with the consideration of the audience as a homogeneous mass. The economic efficiency of media institutions presupposes the reduction of all significant socio-cultural features of people to insignificant ones. Thus presupposes the maintenance of the audience's qualities of passivity and conformism.

\section{LITERATURE REVIEW}

The influence of mass media on the audience is also associated with the growing stereotyping of cultural materials. In the work devoted to the analysis of social and psychological features of television, Adorno stressed that the stereotype is an important element of the individual's experience organization and therefore the problem is not in the stereotype as such, especially since the technology of television production by its nature can not use stereotypes $[2,95]$. The problem is the functional changes that the 
cultural industry brings. The use of increasingly rigid and alienated stereotypes in television materials leads to the fact that the audience turns, in essence, to clichés. Due to this, people not only lose the true idea of reality, but also gradually find themselves in a situation where the possibility of acquiring real life experience is replaced by a distorted experience gained through contacts with clichéd products of mass communication.

A critical assessment of the mass communication role in the modern world is contained in the works of another Frankfurt school - representative Herbert Marcuse. In his work "one-Dimensional man" (1964) the mass media are considered as the main factor or agent of artificially formed social harmony. It denies the true interests and needs of man [5, 187].

The critical tradition of information analysis and mass media found its expression in the works of the American sociologist C. R. Mills. He stressed that, when considering the situation from the point of democratic politics view, a problem inevitably arises. It is obvious that there is a contradiction between the primary "public", i.e. between groups of interpersonal communication, involving an active exchange of views, and the lack of feedback between citizens and the media $[6,25]$.

Trends in the formation of mass society suggest the destruction of the primary public and Amateur associations and replace them with inert "masses", "crowd". It is characterized by irrationality and manipulability.

\section{RESULTS}

It was found that the level of education is one of the most important factors influencing of the audience information needs formation.

Prior to secondary education, there is a process of increasing information needs, increasing the use of mass media, and the role of television in people who have not received secondary education is particularly rapidly increasing. The subsequent increase in the level of the audience education has no significant impact on the information needs. At the same time, in relation to television, there are differences in the socio-demographic groups of the audience. In groups with technical, agricultural, economic higher education, the influence of television remains relatively high, while people with higher education in the Humanities put other sources in the first place, leaving television as an informant about current events in cultural and political life and entertainment [9, 87].

In this context, we can say that an increasing number of researchers are studying the positive qualities of mass communication in modern society. These doubts are rooted in the fact that live contact with a true culturally distinctive phenomena is lost, replaced by reproduction, mediated by perception; the full assimilation of information is replaced by the adapted, simplified forms; active attitude to information is forced out of its passive consumption, regulated and standardized perception. Mass media under the guise of mass education began to form a unified worldview. The average model of the world by making the audience not systematic knowledge, and the amount of specially selected and carefully organized information. At the same time, information saturation is replaced by entertainment. It of course, creates a consumer-friendly attitude to any information with which the recipient works. A simplified view of the world is formed. It contributes to the increase of social infantilism, controllability, adjustability of individual behavior. It loses the status of a full-fledged Communicator and is considered as a passive consumer of dosed information.

The negative aspects of the information use include an individualistic approach aimed at achieving immediate benefits at the expense of other individuals and society. Possessing information and releasing it in "portions" in the necessary interpretation to achieve the desired reaction from others, which is essentially an information manipulation, the informant encourages the action of the one to whom the information is transmitted, whether it is an individual or a group of persons. This motivation can be expressed both in direct form. When there is a presentation of information in someone's interests, and indirect. Both lead to the manipulation of people's behavior. This approach is opposite to the elite individual consciousness and is based on the average ("low" from the point of view of "high culture") tastes, standardized behavioral reactions ("herd behavior") and, in fact, is not consciousness, and its fabricated surrogate. We can see examples in our days when bloodshed on the basis of religious issues, inter-ethnic disputes, etc., does not stop. Skilfully distorted information can lead to the actions of hundreds of people who are trying to restore justice, but do not want to understand the essence of the problem. And this crowd can become a weapon in someone's hands. Here again the words of Tard: "the Crowd is a "wild, mad, unrestrained beast", "blind toy of their instincts and routine habits, and sometimes resembles an invertebrate of the lower order, a kind of monstrous worm." Tard especially resisted the crowd's "unanimity" and homogeneity of ideas and beliefs. They are always, he argued, "the result of one-sided imitation." The crowd is flat-bottomed, stupid and incapable of either great action or creativity - both are belonging only to the personality, and the personality in the crowd is invariably suppressed, extinguished, drowned, ruthlessly crushed by it $[12,114]$.

If only mass behavior prevails, individual behaviors are eliminated. As a result, more predictable human reactions are excluded from the repertoire of behavior. The crowd itself increases the craving for types of unauthorized behavior, as a person is protected by his anonymity. It should be remembered that the aggressiveness of the crowd is a natural psychological reaction to relieve tension due to the presence of an unattainable goal.

Friedrich Nietzsche says about the herd instinct: "the Reproaches of conscience and the most conscientious person are weak compared to the feeling: "this and that is contrary to the good tone of your society." Even the strongest are still afraid of those among whom and for whom he is brought up. What is there to be afraid of? Loneliness! - this argument before which even the best 
arguments in favor of any person or business recede! - So the herd instinct speaks in us" [10, 200].

Isn't this the crisis of culture and humanity that Albert Schweitzer was talking about? The main feature of the crisis is the domination of material life over spiritual life, society over man, depersonalization and demoralization of the latter. Because man falls into modern society in dependence, organizing his "madness", turning to evil his good intentions. Man becomes the embodiment of the blind will that trampled on the last remnants of humanity and makes man serve the perfect means of destruction, without analyzing the warring and not fighting. But Schweitzer found the reason for this in the spread of an erroneous worldview that misinterprets the meaning of culture [13, 41].

Sometimes a person, wishing to be informed, to live in step with the times, to follow the latest trends and achievements of the time, obeys, without noticing, the rules, laws and norms that social information dictates to him in its various manifestations. All people, without exception, should be able to benefit from the global information society $[4,584]$. Here a huge role is played by a personal example of popular and beloved actors, singers, politicians; commercials and brochures, where a bright and beautiful picture promises us everything that we want to get from life: health, love, loyal friends, a successful career. This aspect is vital for advertising, PR, consulting, communication psychology and many other industries.

The amount of information produced and consumed in the modern world is growing rapidly. Today, a person receives more information per day than just recently in his entire life. Analysts predict that in 2003, the average company will need only a day to generate 1 terabyte of data; and in 2004, 10 terabytes of data will be produced per day. Manufacturers of computer software have to introduce a new unit of information storage - petabytes (1024 terabytes). The question of whether the increase in the amount of information leads to a decrease or increase in entropy has not yet been resolved (information theory and Cybernetics answer this question in the opposite way).

\section{CONCLUSION}

It is obvious that "mass consciousness" as a product, and "mass media" together with "mass culture" as a means of production of this product, play a positive role in maintaining the unity of society and its smooth functioning and negative in the self-identification of the individual, turning him into a person. Speaking semiotically, the formation of mass consciousness involves not so much reliance on the same type of texts as nurturing the habit of using the same type of interpretation codes.

Thus, we can only guess what the Age of information brings us - whether the perfect transformation of man and society and the victory over the "laws of nature" known to us, or the achievement of a critical "omega Point", when the amount of accumulated knowledge will become infinite, and the world will turn into chaos and "information will no longer be".

\section{References}

[1] Arnaud T., Horkheimer M. Dialectic of enlightenment. Philosophical fragments. Translated from the German by M. Kuznetsova, M. SPb.: Medium, Juventus. 1997, 312.

[2] Adorno T. How to Look at television. New York. 1954, 145.

[3] Afanasev V. G. The Social information. M.: Science. 1994, 201.

[4] Betelin V.B. Problems and prospects of education in post-industrial information society. Herald of the Russian Academy of Sciences. 2019, vol. 6, pp. 582-592.

[5] Frankl V. Man in search of meaning. M.: Progress. 1990, 213.

[6] Dobrenkov V. I. Sociology: in 3 vol. 1: Social institutions and processes. M.: INFRA-M. 2000.

[7] Marcuse G. One-dimensional man. Kiev. 1994, 267.

[8] Habermas J. The Structural Transformation of Public Sphere: Polity. 1989, 316.

[9] Mills R. Ruling elite. M.: DirectMedia Publishing. 2007, 51.

[10] Nalimov V. V. In search of other meanings. M.: Progress. 1993, 280.

[11] Nietzsche F. Beyond good and evil. Op. T. 2. M. 1990, 367.

[12] Seitel F. The practice of public relation. N. Y. 1992, 128.

[13] Thomson J. B. Ideology and Modern Culture. Oxford: Polity Press. 1990,270

[14] Tikhoplav T. S. Physics of faith. SPb.: "ALL". 2001, 150.

[15] Varganov, V. V., "Attribute" approach in a philosophical analysis of the concept "information". Philosophy in the XXI century: international collection of scientific works. Issue. 9. Voronezh: Voronezh state University. 2006, pp. 200-208.

[16] Ponomareva, T.A. Intentional Values of Physical Culture Among Students. Pedagogico-psycological and medico-biological problems of physical culture and sport. 2017, vol. 12(1), pp. 54-59. DOI: 10.14526/01_2017_186. 